everywhere that ideas of matter and force are distinctly separated or entirely confused, according to the action of the different phenomena of nature on the senses. In New Zealand, the Maoris held that night was the first god, because they thought night produced the day. Heaven was next; then earth; then their children, the gods of light, the sea, etc. They thought that everything was the organ of a special god, or father, or demon, who made it, and kept it what it was. Thus they deified meteors, rainbows, sharks, ants, rats, or any image, to which they gave their own shape and properties.

Among the wild tribes of America, the Great Spirit is the highest member of a group, a personification of the mightest of all natural energies; the sun, God. The living sun itself is not a symbol, but an actual god. The moon is the evil spirit, capricious and changeful. An animal or thing that is worshipped is not a symbol of this or that divine natural power, but becomes altogether a god, a fetish, or spell, or magical charm.

Even if we look to the origin of our own ideas, we shall find that the belief in the existence of four elements - earth, air, fire, water-which has lasted down to the infancy and perhaps beyond the maturity of some now alive, is quite sufficient to prove that we once had our ideas of force or fire entirely separable from our ideas of the three different conditions in which matter may occur. We have all gone through the primitive stage of ideas, in which matter is entirely separable from

The second or transition stage of ideas consists in an incomplete separation between the ideas of matter and force. In this stage, force is considered as altogether separable from ponderable matter, but perfectly inseparable from an imponderable æther, gas, or fluid, which is capable of being attached for a time to the imponderable matter.

The first trace of the idea that force is imponderable matter seems to have started from Kepler; he used it to account for the motions of the planets. He thought that a current of fluid matter circulated round the sun, carrying the planets with it like a boat in a stream. He says the vehicle of that virtue which urges the planets, circulates through the spaces of the universe after the manner of a river or whirlpool (vortex), moving quicker than the planets. He asserted these vortices to be an " immaterial species," capable, however, of overcoming the inertia of bodies. Thence come the vortices of Descartes, by which he showed how the world must have been constructed, and thence the agitation of the æther of Leibnitz; and then follows Newton, who may rightly give his name to this stage of our ideas on matter and force; for Newtonian ideas on matter and force have continued in consequence of his authority down to the present time. Even with regard to gravity, Newton refused to entertain the third stage of ideas. In his second letter to Bentley, I693, he says: "You sometimes speak of gravity as essential and adherent to matter. Pray do not ascribe that notion to me. The cause of gravity I do not pretend to know, and would take more time to consider of it." He seems to have been disposed to refer the tendency of bodies to a centre to the elasticity of an æther. It was, however, in his ideas of light that Newton held the imponderable materiality of force. Descartes said that light consisted of small particles emitted by the luminous body. $\mathrm{He}$ compares these particles to balls, and endeavours to explain, by means of this comparison, the laws of reflection and refraction. Hooke proposed the theory of undulations, and asserted that light consisted in a quick short vibratory motion propagated in a homogeneous medium. Huggins says Whewell would have established the undulatory theory, but Newton, though at first by no means averse to the assumption of an æther as the vehicle of luminiferous undulations, and even to the last considering the assumption of an æther as highly probable, and its vibrations as important parts of the phenomena of light, yet made the emission ideas the leading part of his optical doctrines. "His disciples found it more easy to conceive the motions of a particle than the propagation of a wave, and the general ascendency of the Newtonian doctrines led to a belief in the materiality of light." Newton's ideas of the actual emission of some substance as the cause of light lasted until the time of Dr. Young and Fresnel. The materiality of light led directly to the assumption of the materiality of heat. Lambert, in 1755 , published an essay on the force of heat, in which he likens the communication of heat to the flow of a fluid. To account for the phenomena of heat, a com.

* "In the origin of some of the latest religions, the separability of matter and force is distinctly seen. In 1792 , Johann Schünherr felt that he had got the results of nature in his grasp. Light is the male vivifier; water the female, the nurse. These two arch-beings, the supreme male and supreme female, bound in eternal and in necessary wedlock, explain everything; for in this great wedlock of principles lies the only chance of the seed of things being brought to life. Schönherr felt that this sudden gift of insight was no accident of time and place. It must be more: a revelation from on high; a working of celestial love in his soul; a pouring of the divine will into his spirit. One day he went to Emmanuel Kant, to whom he wished to will known his grand secret, that all living things consist of light and he wished to make said the expounder of pure reason, "have you tried to live on them?"-Dixon. bustible element, an igneous matter, capable of combining or separating itself from other substances, was assumed; this was phlogiston. It was considered, until the time of Black and Lavoisier, as just as much a chemical element as any ponderable element. It was assumed even to have a principle of lightness. The imponderable materialism of heat, however, survived in the idea of caloric; material heat was an actual flow and emission of material particles. Leslie, in 1804, says, "What is this calorific and frigorific fluid?" It is merely the ambient air. But afterwards he says, "It is the same subtle matter that, according to its different modes of existence, constitutes either heat or light." Even as late as 1832, in the Bibliothèque Universelle de Génève, vol. 49, and again in 1834, in the Annales de Chimie, vol. 58, M. Ampère published his views on heat and light considered as results of the vibratory motion of the imponderable æther.

The imponderable materialism of the electric and magnetic force commenced with the same stage of ideas regarding heat. In 1733 , Dufay proposed the idea of two electric fluids, each repelling its own parts or attracting those of the other. Franklin assumed only one fluid, repelling itself and attracting all other matter. In 1803, Dr. Thomas Young, in the Fournal of the Royal Institution, vol. i, p. 103, gives his ideas regarding the imponderable material substance which, when present in different bodies, gives rise to electricity. "Perhaps," he says, "some antiphlogistian will soon give us a chemical analysis of the electric fluid. Might I be permitted such a doctrine, it should be that it consists of oxygen and hydrogen combined with caloric only." And in the Annals of Philosophy, new series, vol. ii, p. 196, Sept., 1821, Mr. Faraday says, "There are many arguments in favour of the materiality of electricity, and but few against it; but still it is only a supposition, and it will be as well to remember, while pursuing the subject of electro-magnetism, that we have no proof of the materiality of electricity, or of the existence of any current through the wire."

With regard to the imponderable materiality of the magnetic force. Descartes considered magnetic curves to be the traces of currents of æatherial matter, which are thus rendered sensible even to the eye. According to Epinus, the phenomena of the opposite poles arose from an excess or defect of a magnetic fluid. Coulomb assumed an austral and a boreal fluid instead of a single fluid; Whewell says the hypothesis of magnetic fluids, as physical realities, was never so widely or strongly embraced as that of two electric fluids. There was no spark, shock, discharge, or mechanical effects. He continues, "if we doubt regarding electric fluids, we cannot help pronouncing upon the magnetic fluids as having still more insecure claims to a material existence. They must be regarded as different effects of one common cause. No philosopher would dream of assuming electric fluids and magnetic fluids as two distinct material agents. Thus, then, in the second stage of ideas of matter and force, force is made quite inseparable from imponderable matter, although this is considered to be perfectly separable from ponderable matter. In other words, there is an incomplete separation between the ideas of matter and force.

( To be concluded.)

\section{CASE OF VACCINO-SYPHILITIC INOCULATION.}

\section{By CHARLES DRYSDALE, M.D.,}

Physician to the Farringdon General Dispensary.

RosA B., I4 weeks old, was seen June 4 th, 1866. The child had a dry scaly eruption on the buttocks, and had some mucous tubercles at the anus; also a café au lait colour of the chin and the skin around the mouth. There were cracks at the corners of the mouth. Two of the posterior cervical and one of the occipital glands were enlarged. She was moderately thin, not emaciated. There was obstruction to the breathing, or "snuffles." The child, it appeared, was born quite healthy, and remained so until some time after it was vaccinated, which event took place when it was nine weeks old. The eruption appeared four weeks after the vaccination, or a week before the child was first seen. On inspection by myself and Mr. R. W. Dunn of the scars left by the vaccination, they were seen to be copper-coloured, and a distinct induration was remarked at the spot. The mother was 34 years of age, and had been married five years: she had always been well, and had healthy children. One born since that time is now (March 1868) in perfect health. One girl, three years old, was at that date quite well. Her husband, employed in the post-office, came at my request, and presented not the slightest trace or history of syphilis. The child became much better for a time on chlorate of pntash; and afterwards, during $m y$ absence from town, was reported to have died in August. 